\title{
Ketamine and Ro 25-6981 Reverse Behavioral Abnormalities in Rats Subjected to Dietary Zinc Restriction
}

\author{
Bartłomiej Pochwat ${ }^{1, *}$, Helena Domin ${ }^{2}$, Anna Rafało-Ulińska ${ }^{1}$, Bernadeta Szewczyk ${ }^{1}$ \\ and Gabriel Nowak ${ }^{1,3, *}$
}

1 Maj Institute of Pharmacology, Polish Academy of Sciences, Department of Neurobiology, Laboratory of Trace Elements Neurobiology, Smetna street 12, 31-343 Krakow, Poland; rafalo@if-pan.krakow.pl (A.R.-U.); szewczyk@if-pan.krakow.pl (B.S.)

2 Maj Institute of Pharmacology, Polish Academy of Sciences, Department of Neurobiology, Smetna street 12, 31-343 Krakow, Poland; domin@if-pan.krakow.pl

3 Department of Pharmacobiology, Faculty of Pharmacy, Jagiellonian University Medical College, 9 Medyczna Street, 30-688 Kraków, Poland

* Correspondence: pochwat@if-pan.krakow.pl (B.P.); nowak@if-pan.krakow.pl (G.N.); Tel.: +48-126623362 (B.P.); +48-126623215 (G.N.); Fax: +48-126374500 (B.P. \& G.N.)

Received: 2 June 2020; Accepted: 2 July 2020; Published: 6 July 2020

\begin{abstract}
Clinical and preclinical studies indicate that zinc $(\mathrm{Zn})$ is an essential factor in the development and treatment of major depressive disorder (MDD). Conventional monoamine-based antidepressants mobilize zinc in the blood and brain of depressed patients as well as rodents. N-methyl-D-aspartate acid receptor (NMDAR) antagonists exhibit antidepressant-like activity. However, not much is known about the antidepressant efficacy of NMDAR antagonists in zinc-deficient $(\mathrm{ZnD})$ animals. We evaluated the antidepressant-like activity of two NMDAR antagonists (ketamine; global NMDAR antagonist and Ro 25-6981 (Ro); selective antagonist of the GluN2B NMDAR subunit) in ZnD rats using the forced swim test (FST) and sucrose intake test (SIT). A single dose of either Ro 25-6981 or ketamine normalized depressive-like behaviors in $\mathrm{ZnD}$ rats; however, Ro was effective in both tests, while ketamine was only effective in the FST. Additionally, we investigated the mechanism of antidepressant action of Ro at the molecular (analysis of protein expression by Western blotting) and anatomical (density of dendritic spines by Golgi Cox-staining) levels. $\mathrm{ZnD}$ rats exhibited decreased phosphorylation of the p70S6K protein, and enhanced density of dendritic spines in the prefrontal cortex (PFC) compared to control rats. The antidepressant-like activity of Ro was associated with the increased phosphorylation of p70S6K and ERK in the PFC. In summary, single doses of the NMDAR antagonists ketamine and Ro exhibited antidepressant-like activity in the $\mathrm{ZnD}$ animal model of depression. Animals were only deprived of $\mathrm{Zn}$ for 4 weeks and the biochemical effects of $\mathrm{Zn}$ deprivation and Ro were investigated in the PFC and hippocampus. The shorter duration of dietary $\mathrm{Zn}$ restriction may be a limitation of the study. However, future studies with longer durations of dietary $\mathrm{Zn}$ restriction, as well as the investigation of multiple brain structures, are encouraged as a supplement to this study.
\end{abstract}

Keywords: ketamine; Ro 25-6981; zinc deficiency; depression

\section{Introduction}

Major depressive disorder (MDD) is a serious medical problem that generates enormous economic and social costs globally. The morbidity associated with this disease has been on the increase [1-3] and therefore presents a considerable challenge in terms of effective treatment strategies. 
There are still gaps in the understanding of the biological mechanisms underlying MDD, with no definitive therapy at the moment. Currently used monoamine-based antidepressant drugs are not effective in a high percentage of people who suffer from MDD [4]. Meanwhile, the crucial biological factors involved in the pathophysiology of MDD are not known. Therefore, new studies on more effective therapies for MDD and a better explanation of the social and biological causes of this illness are warranted.

Some evidence indicates that lifestyle, including diet, maybe a risk factor for the development of MDD [5]. Among others, decreased dietary intake of Zn may be a risk factor for the development of MDD. A few epidemiological reports have suggested an association between MDD and decreased dietary $\mathrm{Zn}$ intake [6,7]. Other studies have shown negative correlations between reduced serum $\mathrm{Zn}$ levels and the severity of MDD symptoms [8,9]. Additionally, decreased serum $\mathrm{Zn}$ levels have been reported in MDD patients [10-13]. Interestingly, in some MDD patients, blood $\mathrm{Zn}$ levels have been normalized after antidepressant treatment [14]. Both the lack of zinc normalization and reduced blood zinc levels have also been described in patients with refractory depression $[9,15,16]$. The role of $\mathrm{Zn}$ in the development of MDD symptoms is equally evident in preclinical paradigms. Chronic dietary Zn restriction evoked depressive-like symptoms in mice, with increased immobility time in the forced swim test (FST) and the tail suspension test [17-19].

Similar behavioral consequences of zinc deficiency have been reported in rats. Rats fed with a low Zn diet exhibited longer immobility time in the FST, reduced sucrose intake, and reduced social interactions [20-22]. Increased immobility time in the FST in ZnD rats was normalized by two weeks of treatment with the serotonin selective reuptake inhibitor (SSRI) fluoxetine [21]. However, it should be emphasized that the relationship between $\mathrm{ZnD}$ and the efficacy of particular antidepressant strategies is not fully understood.

Recently, ketamine and other NMDAR antagonists have been extensively evaluated as potential antidepressant drugs [23,24]. In clinical studies, a single dose of ketamine induced rapid and long-lasting antidepressant response $[25,26]$. What is very important and unique is that ketamine or its enantiomer (S)-ketamine was also effective in the treatment of resistant depression [25-28] and MDD with suicidal ideations [29-31]. Moreover, ketamine and other NMDAR antagonists such as Ro and MK-801 reversed behavioral abnormalities in animal models of depression $[32,33]$. Because $\mathrm{ZnD}$ causes behavioral abnormalities akin to chronic stress, we asked the question-do atypical glutamate-antidepressant compounds such as ketamine and Ro exhibit antidepressant-like activity in $\mathrm{ZnD}$ rats? This question is important because $\mathrm{Zn}$ is an endogenous antagonist of NMDAR and is released alongside glutamate from zincergic neurons in brain regions such as the hippocampus (Hp) and PFC, areas involved in mood regulation [34-37]. Furthermore, in contrast to classic antidepressants, NMDAR antagonists (ketamine, MK-801) induce an antidepressant-like response in GPR39 receptor knockout mice. GPR39 is an endogenous receptor that is positively modulated by Zn [38]. Therefore, these results suggest that NMDAR antagonists can also be active under conditions where zinc-dependent signaling pathways are disrupted. In other words, because NMDAR antagonists are effective in GPR39 knockout mice, they may likely function independently of Zn levels as well. To address the question concerning NMDAR antagonists in $\mathrm{ZnD}$ rats, we performed a few behavioral tests such as SIT, FST, and locomotor activity (LA) test following the administration of a single dose of either ketamine or Ro to rats exposed to 4 weeks of dietary $\mathrm{Zn}$ restriction. Based on our results, we chose Ro to carry out biochemical and anatomical studies. The antidepressant-like activity of Ro is dependent on the activation of intracellular signaling pathways such as extracellular regulated kinase (ERK), p70S6K-dependent synthesis of synaptic proteins, including synapsin I and the GluA1 subunit of glutamate $\alpha$-amino-3-hydroxy-5-methyl-4-isoxazolepropionic acid receptor (AMPAR) acid [33,39,40]. Both the ERK and p70S6K signaling pathways are involved in the synthesis of synaptic proteins and remodeling of dendritic spines. Therefore, the goal of this study was to ascertain whether the same molecular mechanisms are responsible for the antidepressant-like activity of Ro in $\mathrm{ZnD}$ rats. 
Consequently, we measured the expression of these proteins in the PFC, $\mathrm{Hp}$, and investigated the density of dendritic spines in the cingulate (Cg3) and infralimbic (IL) cortex.

\section{Results}

\subsection{Effects of Ro and Ketamine on Immobility Time and Locomotor Activity of ZnD Rats}

$\mathrm{ZnD}$ rats exhibited increased immobility time in the FST; however, ketamine and Ro decreased the immobility time in these rats (Figure $1 \mathrm{~A}-\mathrm{C}$ ). Both ketamine and Ro also reduced the immobility time in zinc-adequate $\mathrm{ZnA}$ ) rats compared to control rats. The effects induced by Ro in the $\mathrm{ZnD}$ rats could be nonspecific because of the increasing trend in locomotor activity observed after Ro administration (Table 1). However, ketamine did not exhibit a similar effect in the LA test (Table 1). Both atypical compounds (Ro and ketamine) showed potential antidepressant-like activity after a single dose.

A

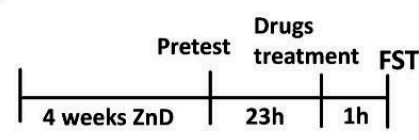

B

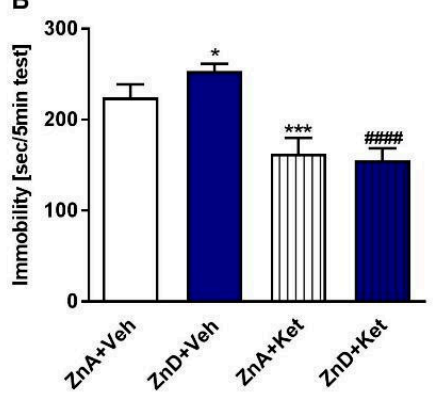

c

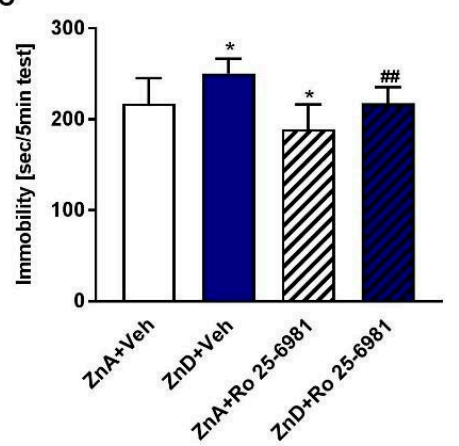

Figure 1. The effect of a single dose of ketamine (Ket) and Ro 25-6981 in the forced swim test (FST) in rats subjected to zinc deficiency. (A) Experimental schedule of drug treatments and behavioral test. Ketamine (10 mg/kg; i.p.), $\mathrm{n}=8-10$ (B) and Ro 25-6981 (10 mg/kg; i.p.), $n=8-9$ (C) were administered $60 \mathrm{~min}$ before the FST. All data were analyzed by two-way ANOVA and Newman-Keuls multiple comparisons test. Values are expressed as mean \pm S.E.M. Two way ANOVA for ketamine showed non-significant interaction $[\mathrm{F}(1,32)=1.794, p=0.1899]$, the significant effect of $\mathrm{ZnD}[\mathrm{F}(1,32)=35.4$, $p<0.0001]$, and the non-significant effect of ketamine $[\mathrm{F}(1,32)=0.6554, p=0.4242]$. Two way ANOVA for Ro 25-6981 showed non-significant interaction $[\mathrm{F}(1,31)=0.1005, p=0.7534]$, the significant effect of $\mathrm{ZnD}[\mathrm{F}(1,31)=15.38, p=0.0005]$, and the significant effect of Ro 25-6981 [F $(1,31)=15.94, p=0.0004]$. ${ }^{*} p<0.05$ vs. ZnA + Veh; ${ }^{* * *} p<0.001$ vs ZnA + Veh; ${ }^{\# \# \# ~} p<0.0001$ vs. ZnD + Veh; ${ }^{\# \#} p<0.01$ vs. ZnD + Veh. ZnA—zinc adequate diet; $\mathrm{ZnD}$-zinc deficient diet.

Table 1. Effect of zinc deficient diet ( $\mathrm{ZnD})$ and Ro 25-6981 and ketamine treatment on the locomotor activity of rats.

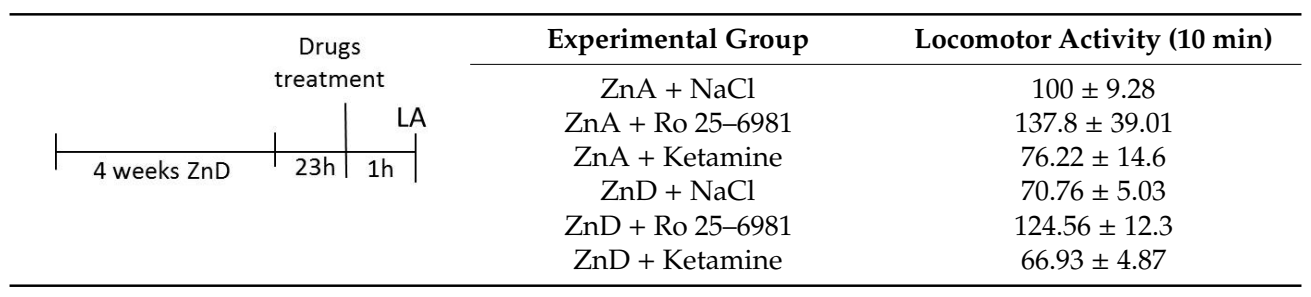

Locomotor activity (distance traveled in $\mathrm{cm}$ ) was recorded for $10 \mathrm{~min}$. and presented as \% of $\mathrm{ZnA}+\mathrm{NaCl}$. All data were analyzed by two way ANOVA and Newman-Keuls multiple comparisons test. Values are expressed as mean \pm S.E.M, $(n=5-7)$. Two way ANOVA showed non-significant interaction $[\mathrm{F}(2,30)=0.2244, p=0.8003]$, the significant effect of $\mathrm{ZnD}[\mathrm{F}(2,30)=7.383, p=0.0025]$, and the non-significant effect of treatment $[\mathrm{F}(1,30)=1.742, p=0.1969]$. Values are expressed as mean $\pm \operatorname{SEM}(n=5-7)$. 


\subsection{Effects of Ro and Ketamine on Sucrose Intake in Rats Subjected to Dietary Zn Restriction}

To further evaluate the antidepressant potency of single doses of Ro and ketamine, we performed the SIT. Only Ro significantly reversed the reduced sucrose intake in $\mathrm{ZnD}$ rats (Figure 2A,B). Although ketamine followed a similar trend, the effect was not statistically significant. Based on these results, we chose to perform further biochemical assays with Ro.

A.

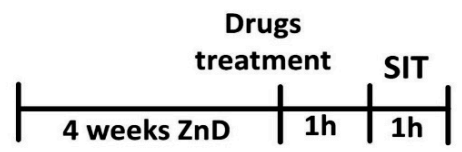

B.

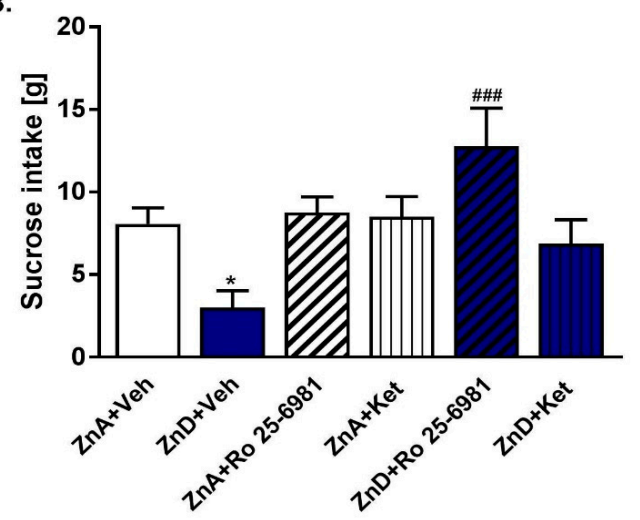

Figure 2. The effect of a single dose of ketamine (Ket) and Ro 25-6981 on sucrose intake in rats subjected to zinc deficiency. (A) Experimental schedule of drug treatments and behavioral test; (B) ketamine (10 mg/kg; i.p.) and Ro 25-6981 (10 mg/kg; i.p.) were administered $60 \mathrm{~min}$ before the test. Data were analyzed by two-way ANOVA and the Newman-Keuls multiple comparisons test. Values are expressed as mean \pm S.E.M. Two-way ANOVA showed significant interaction $[\mathrm{F}(2,44)=5.555 ; p=0.0071]$, the significant effect of $\mathrm{ZnD}[\mathrm{F}(2,44)=7.268 ; p=0.0019]$ and the non-significant effect of treatment $[\mathrm{F}$ $(1,44)=0.6351, p=0.4298] .{ }^{*} p<0.05$ vs. ZnA + Veh; ${ }^{\# \#} p<0.001$ vs. ZnD + Veh $(n=8-9)$.

\subsection{Effects of Ro and ZnD on the Levels of Synaptic Proteins and ERK/p-70S6K Kinases}

The antidepressant-like activity of Ro is dependent on the activation (by phosphorylation) of intracellular proteins such as ERK and p70S6K, the effectors of mTOR and MAPK (mitogen activated protein kinase) intracellular signaling pathways $[39,40]$. Moreover, p70S6K is involved in the process of neuroplasticity which is associated with changes in synaptic proteins such as synapsin I or the GluA1 subunit of AMPA receptors [39,40]. We determined the effects of Ro on the expression of these proteins in the PFC and Hp, brain structures crucial in mood regulation (Figure 3A,B,G). Figure 3C shows that dietary $\mathrm{Zn}$ restriction reduced the ratio of phospho-p70S6K (ph-p70S6K)/p70S6K in the PFC. Administration of Ro reversed these effects. In contrast, ph-p70S6K/p70S6K and phospho-ERK (p-ERK)/ERK ratios were not significantly altered by dietary $\mathrm{Zn}$ restriction (Figure 3D). However, Ro enhanced these ratios in the PFC of $\mathrm{ZnA}$ and $\mathrm{ZnD}$ rats (Figure 3D). No significant changes were seen in the expression of the rest of the proteins (Figure 3E-K).

\subsection{Effects of Ro and ZnD on the Density of Dendritic Spines in the Medial Prefrontal Cortex (mPFC)}

As shown in Figure $4 \mathrm{~A}-\mathrm{B}, \mathrm{ZnD}$ enhanced the density of spines on the secondary and tertiary apical dendrites compared to $\mathrm{ZnA}$ rats in the $\mathrm{Cg} 3$ cortex (Figure 4A) and the IL cortex (Figure 4B). Administration of a single dose of Ro increased the density of dendritic spines in the $\mathrm{Cg} 3$ cortex (Figure 4A) and IL cortex (Figure 4B) of ZnA rats. We did not find statistically significant effects of Ro on dendritic spine density in the $\mathrm{ZnD}$ group, but there was a clear upward trend in $\mathrm{ZnD}$ rats treated with Ro. 
A.

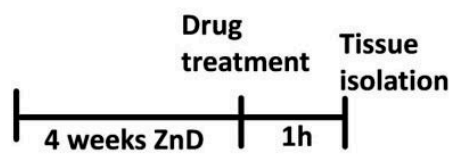

Prefrontal Cortex

B.

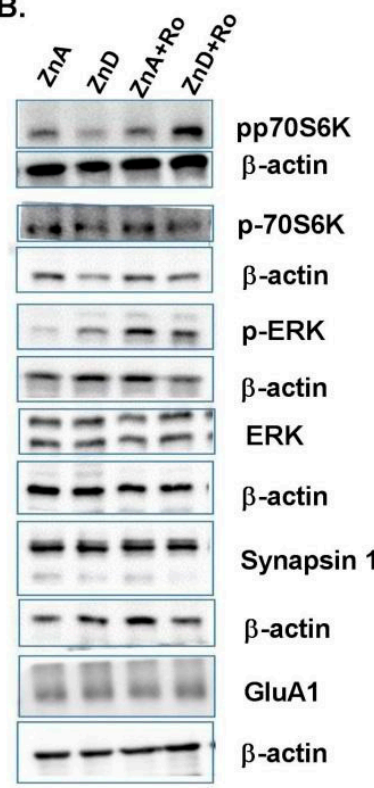

Hippocampus

G.

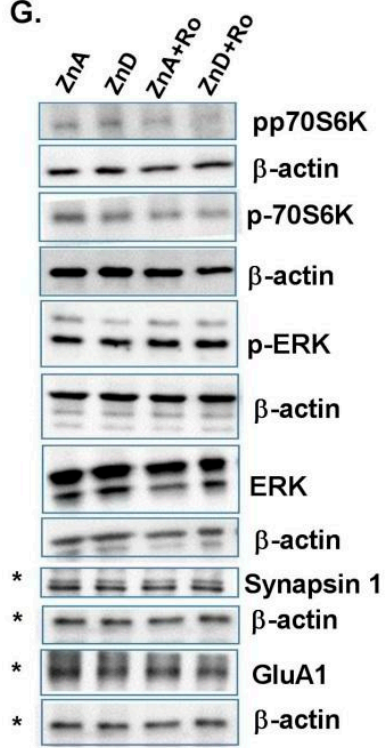

C.
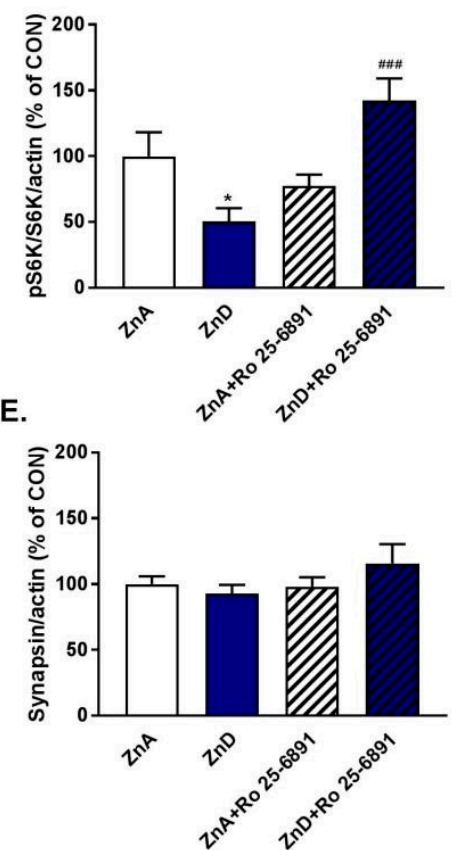

$\mathrm{H}$.

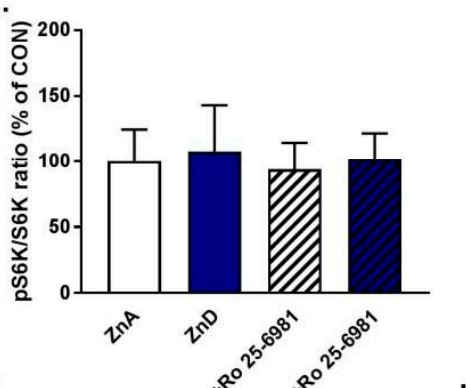

J.

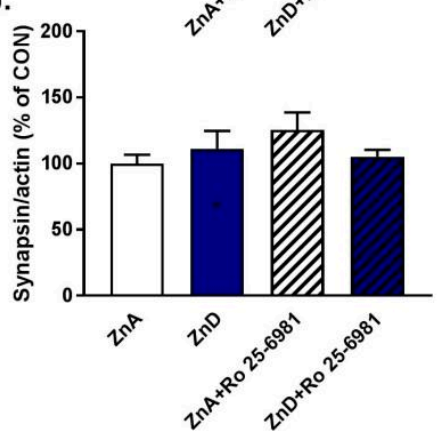

F.

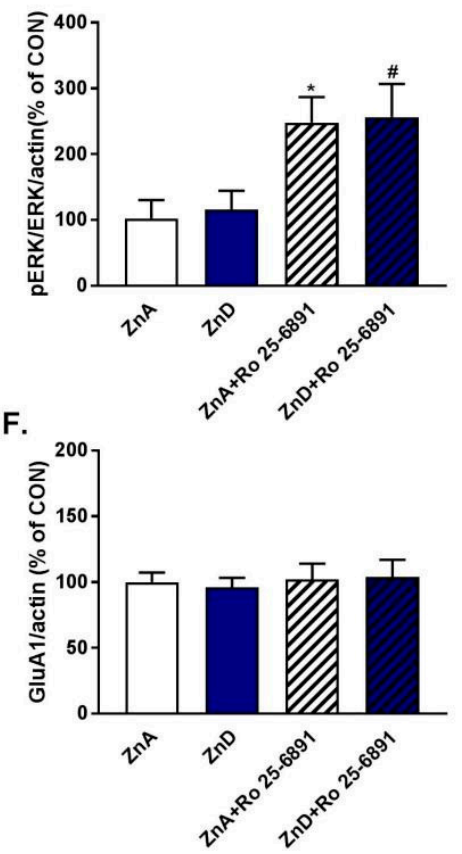

D.

I.
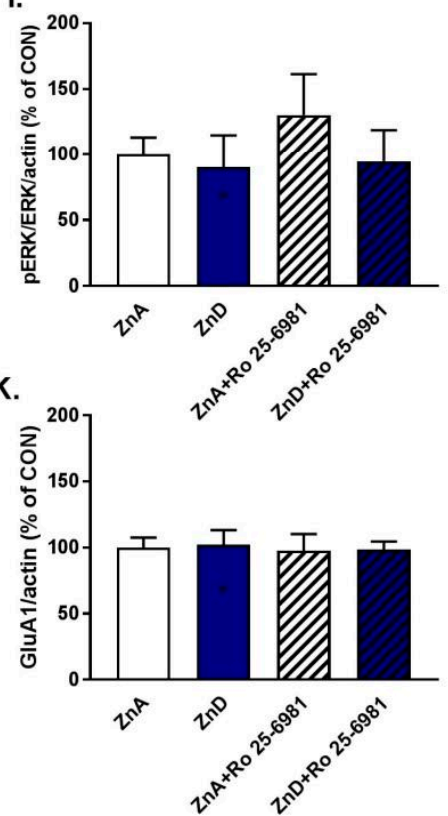

Figure 3. The effect of the administration of single dose of Ro 25-6981 on the expression of pS6K/S6K, p-ERK/ERK, synapsin I and GluA1 subunit of AMPA receptors in the prefrontal cortex (PFC) and hippocampus $(\mathrm{Hp})$ of rats subjected to $\mathrm{ZnD}, n=8-10$; (A) experimental schedule; (B) representative blots for PFC; (C-F) protein expression in PFC; $(\mathbf{G})$ representative blots for $\mathrm{Hp}$, ${ }^{*}$ images from the same part of the membrane; $(\mathbf{H}-\mathbf{K})$ protein expression in Hp. All data were analyzed by two-way ANOVA and the Newman-Keuls multiple comparisons test. All values are expressed as mean \pm S.E.M. PFC: (B) pS6K/S6K: interaction $[\mathrm{F}(1,31)=17.18, p=0.0002]$; effect of $\operatorname{Ro} 25-6981[\mathrm{~F}(1,31)=6.335, p=0.0172]$; 
effect of $\mathrm{ZnD}[\mathrm{F}(1,31)=0.3069, p=0.5836] ;{ }^{*} p<0.05 \mathrm{vs.} \mathrm{ZnA},{ }^{\# \# \#} p<0.001$; (C) p-ERK/ERK: interaction $[(1,32)=0.0063, p=0.9372]$; effect of Ro 25-6981 [F $(1,32)=14.76, p=0.0005]$; effect of ZnD [F $(1,32)=0.09003, p=0.7661] ;{ }^{*} p<0.05$ vs. $\mathrm{ZnA},{ }^{*} p<0.05$ vs. $\mathrm{ZnD} ;(\mathrm{D})$ Synapsin I: interaction [F $(1,31)=1.981, p=0.1692]$; effect of Ro 25-6981: [F $(1,31)=1.411, p=0.2439]$, effect of ZnD [F (1, $31)=0.3487, p=0.5591]$; (E) GluA1: Interaction $[\mathrm{F}(1,36)=0.07359, p=0.7877]$; effect of Ro 25-6981 [F $(1,36)=0.2268, p=0.6368]$, effect of $\mathrm{ZnD}[\mathrm{F}(1,36)=0.01161, p=0.9148]$; Hp: (H) pS6K/S6K: interaction $\left[\mathrm{F}(1,32)=1.979 \times 10^{-6}, p=0.9989\right]$; effect of Ro 25-6981 [F $\left.(1,32)=0.05986, p=0.8083\right]$; effect of ZnD [F $(1,32)=0.0851, p=0.7724]$; (I) p-ERK/ERK: interaction $[\mathrm{F}(1,32)=0.2892, p=0.5944]$; effect of Ro 25-6981 [F (1, 32) = 0.5073, $p=0.4815]$; effect of $\mathrm{ZnD}[\mathrm{F}(1,32)=0.8807, p=0.3550]$; (J) Synapsin I: interaction $[\mathrm{F}(1,32)=2.334, p=0.1364]$; effect of Ro 25-6981: $[\mathrm{F}(1,32)=0.899, p=0.3502]$, effect of $\mathrm{ZnD}[\mathrm{F}(1,32)=0.2022, p=0.6560]$; (K) GluA1: Interaction $[\mathrm{F}(1,32)=0.003627, p=0.9523]$; effect of Ro $25-6981[\mathrm{~F}(1,32)=0.09773, p=0.7566]$, effect of $\mathrm{ZnD}[\mathrm{F}(1,32)=0.02311, p=0.8801]$.

A

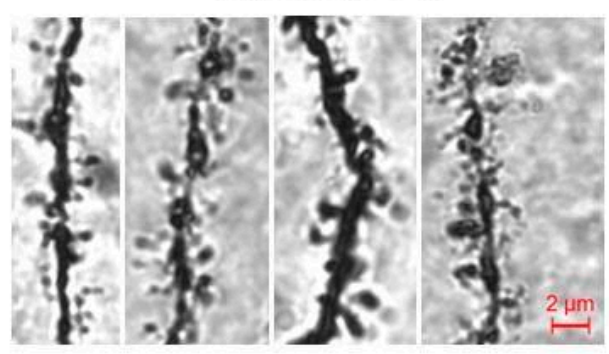

B

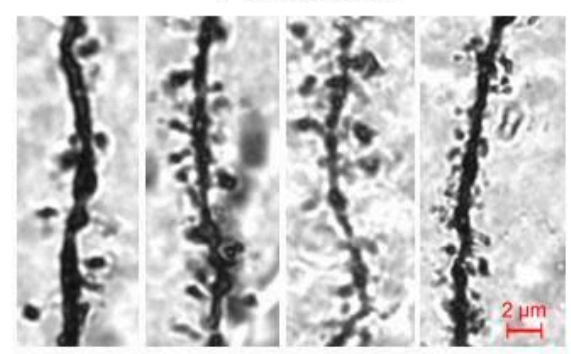

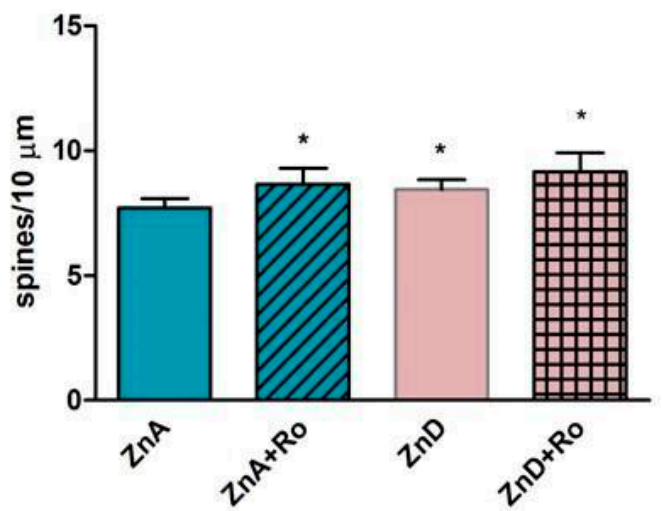

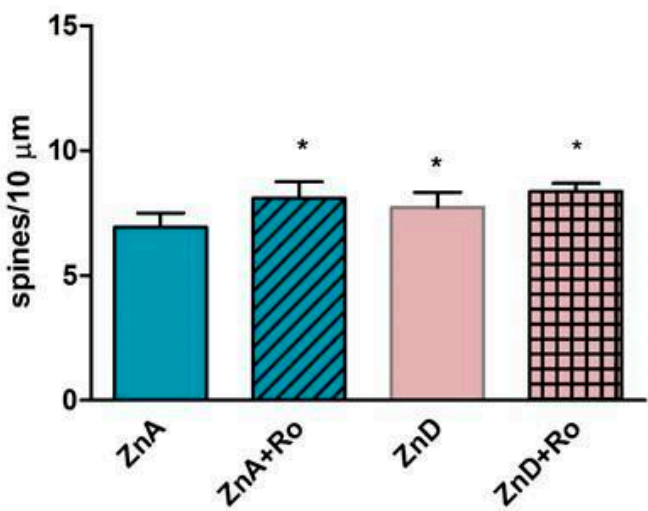

Figure 4. The effect of a single dose of Ro 25-6981 on density of dendritic spines in the Cg3 cortex (A) and IL cortex (B). Ro 25-6981 (10 mg/kg; i.p.) was administered $180 \mathrm{~min}$ before the decapitation, $n=5-6$. Data were analyzed by two-way ANOVA and the Newman-Keuls multiple comparisons test. Values are expressed as mean \pm S.E.M.; (A) two way ANOVA for Cg3 showed non-significant interaction [F (1, $17)=0.2588, p=0.6175]$, the significant effect of $\mathrm{ZnD}[\mathrm{F}(1,17)=11.29, p=0.0037]$, and the significant effect of Ro 25-6981 [F $(1,17)=6.498, p=0.0207]$; (B) Two way ANOVA for IL showed non-significant interaction $[\mathrm{F}(1,16)=1.178, p=0.2938$, the significant effect of $\mathrm{ZnD}[\mathrm{F}(1,16)=13.07, p=0.0023]$ and the significant effect of Ro 25-6981 [F $(1,16)=4.692, p=0.0457] .{ }^{*} p<0.05$ vs. ZnA + Veh.

\section{Discussion}

Both clinical and preclinical evidence indicates that lower intake of dietary of zinc may be associated with MDD symptoms in humans and depressive-like behaviors in rodents $[9,15,19,21]$. Also, the negative relationship between serum $\mathrm{Zn}$ levels and the response to monoamine-dependent antidepressant drugs in humans has been reported $[9,15,16,21]$. In contrast, a few preclinical studies 
have shown that chronic treatment with classic drugs such as fluoxetine or desipramine reversed the depression phenotype induced by dietary $\mathrm{Zn}$ restriction in rats and mice [19,21].

From a mechanistic standpoint, we have previously shown that dietary Zn restriction in rats reduced the levels of this microelement in the serum, Hp, and PFC of rats. The reduction was accompanied by increased glutamate release in the PFC after $\mathrm{KCl}$ stimulation [19-21,41]. Since Zn blocks NMDAR and is crucial for the proper functioning of glutamatergic/zincergic neurons in the hippocampus and PFC [34-37,42], we wanted to find out whether Zn depletion has an impact on the antidepressant response of glutamate-based atypical compounds. Thus, we examined the antidepressant-like effects of single doses of fast-acting, atypical compounds (Ro and ketamine) in rats subjected to 4 weeks of dietary $\mathrm{Zn}$ restriction. Both Ro and ketamine exert their primary effects through interaction with the glutamate system, albeit differently. Ro selectively blocks NMDAR containing the GluN2B subunit, while ketamine globally blocks NMDAR [43].

Here, we show that a single dose of ketamine and Ro reduced immobility time in $\mathrm{ZnD}$ rats in the FST. Because Ro, in contrast to ketamine, showed the trend to enhance locomotor activity, its antidepressant efficacy in the FST should be interpreted with caution, as these effects could be nonspecific. Because we previously found that $\mathrm{ZnD}$ rats exhibited reduced sucrose intake compared to $\mathrm{ZnA}$ animals [20], we further evaluated the antidepressant-like activity of both compounds in this behavioral test. We confirmed our earlier observations that dietary $\mathrm{Zn}$ restriction decreases sucrose intake. Moreover, we found that only Ro reversed the effect induced by $\mathrm{ZnD}$ in a statistically significant manner. While ketamine also increased sucrose intake in $\mathrm{ZnD}$ rats, the effect was not statistically significant. It is known that a single dose of either ketamine or other NMDAR antagonists like Ro induces antidepressant-like potency in preclinical stress-related paradigms [32,44,45]. On the other hand, classic antidepressant drugs like fluoxetine or desipramine are effective only after chronic treatment $[19,21]$. Thus, our results suggest that $\mathrm{ZnD}$ may serve as a potential animal model of depression with similar predictive validity to the better-known stress-dependent paradigms.

We also wanted to find out what kinds of mechanisms underlie the antidepressant-like activity of NMDAR in ZnD rats. Because Ro was more potent than ketamine in the behavioral tests, we used Ro for our biochemical experiments. There are indications that the potential antidepressant mechanism of Ro involves the activation of intracellular signaling pathways such as ERK and mTOR/p70S6K and the enhanced expression of synaptic proteins, including synapsin I or the GluA1 subunit of AMPAR [32,39]. The expression and activation of these proteins are crucial for the processes of neuroplasticity, which are perturbed in animal models of depression [23]. Moreover, the disruption of neuroplasticity defined as a decrease in synaptic plasticity-related proteins and reduced density of synaptic spines has been reported in $\mathrm{ZnD}$ mice, induced by the chronic administration of clioquinol, a known $\mathrm{Zn} /$ copper chelator [46]. Since a dysfunction in neural plasticity has been reported in the Hp and PFC in animal models of depression [47,48], we chose these same regions for our assays. Our results reveal that ZnD did not alter the expression of the GluA1 subunit of AMPAR, synapsin I, and p-ERK/ERK ratio in the $\mathrm{Hp}$ or PFC. However, the ratio of ph-p70S6K/total p70S6K was significantly reduced in the PFC but not $\mathrm{Hp}$ of $\mathrm{ZnD}$ rats. Importantly, a single dose of Ro restored the ratio of ph-p70S6K/total p70S6K in $\mathrm{ZnD}$ rats. p70S6K regulates the translation of synaptic proteins like the GluA1 subunit of AMPAR or synapsin I. Our results do not reveal any effect of Ro on the expression of synaptic proteins.

Nevertheless, we should mention that the brains used for protein expression studies were harvested $1 \mathrm{~h}$ after Ro treatment. Ro's influence on the expression of synapsin I and the GluA1 subunit are seen after $6 \mathrm{~h}$ after its administration [39]. Therefore, the effects induced by Ro may occur later. Because the reduced activity of p70S6K may be associated with the decreased density of dendritic spines, and that NMDAR antagonists increase the density of dendritic spines in animal models of depression and naive rodents [49-51], we subsequently investigated the effects of $\mathrm{ZnD}$ and Ro on this parameter in the medial prefrontal cortex (mPFC). Contrary to some other preclinical depression paradigms [49-51], ZnD increased spine density in the mPFC (IL and Cg3 cortex). In addition, Ro elevated spine density in control animals in a statistically significant manner. This trend was also 
observed in $\mathrm{ZnD}$ rats following treatment with Ro; however, this was not statistically significant. These outcomes may suggest that the reduction in dendritic spine density in the MPFC is not involved in the induction of depressive-like behaviors observed in $\mathrm{ZnD}$ rats.

Additionally, our studies showed that zinc deficiency induced by dietary Zn restriction evoked different brain changes compared to that caused by chelators in mice (decreased density of spines). Another aspect of the studies was the lack of association between spine density and the reduced ratio of ph-p70S6K/totalp70S6K in ZnD rats. This phenomenon can be explained by the fact that spine density can be controlled by the interplay between many intracellular signaling pathways, such as the ERK $\mathrm{mTOR} / \mathrm{p} 70 \mathrm{S6K}$ pathway [52]. Therefore, the activity of ERK kinase is also very important for dendritic spine formation. In $\mathrm{ZnD}$ rats, we did not observe alterations in the ratio of phospho-ERK/total ERK. In stress-related paradigms, the reduction in cortical spine density correlated with decreased levels of ERK and p70SK phosphorylation [52-54]. Thus, it is very plausible that proper dendritic spine density requires the interaction of ERK and S6K kinases. Recently, we showed that ERK phosphorylation is indispensable for Ro antidepressant-like activity [40]. Our results show that Ro treatment results in an enhanced ERK phosphorylation in both $\mathrm{ZnD}$ and $\mathrm{ZnA}$ rats.

In summary, we have confirmed our previous observations that $\mathrm{ZnD}$ induced by dietary $\mathrm{Zn}$ restriction evokes depressive-like behaviors in rats. These behavioral abnormalities are reversed by the administration of a single dose of the NMDAR antagonist ketamine or Ro. The antidepressant-like activity of Ro was associated with the activation of p70S6K and ERK kinases. Our results also confirm that NMDAR antagonists activate intracellular signaling pathways involved in the processes of neuroplasticity. However, the precise role of this signaling pathway in the formation of dendritic spines in $\mathrm{ZnD}$ rats requires further studies. The current studies are important from a clinical standpoint, as they focus on the fact that diet can be an important risk factor in the development of psychiatric disorders like MDD. Moreover, these studies again confirmed that a single dose of an NMDAR antagonist elicits antidepressant efficacy in preclinical conditions.

\section{Material and Methods}

\subsection{Animals}

The experiments were carried out on male Sprague-Dawley rats (Charles, River, Germany) kept under standard laboratory conditions of lighting (light phase: 7:00-19:00) and temperature $\left(19-21^{\circ} \mathrm{C}\right)$, with free access to water and food. All manipulations were carried out between 8:00 and 16:00. All procedures in this study were performed according to the guidelines of the European Community Council (Directive 86/609/EEC). The study was approved by the Ethics Committee of the Maj Institute of Pharmacology at the Polish Academy of Sciences in Krakow (87/2016, 31.05.2016). All efforts were made to minimize animal suffering and to reduce the number of animals used.

\subsection{Drug Administration}

The following drugs were used: ketamine $(10 \mathrm{mg} / \mathrm{kg}$ ) (Biowet Puławy, Poland) was administered intraperitoneally (i.p); Ro 25-6981 maleate (10 mg/kg) (Tocris, Bristol, UK) dissolved in 10\% DMSO (Sigma Aldrich, St.Louis, MO, USA) was administered i.p; the control groups received physiological saline $(0,9 \% \mathrm{NaCl})$ (i.p) or $10 \% \mathrm{DMSO}$ (i.p). For behavioral experiments, drugs were administered one hour before each test. For Western blotting assays, drugs were also administered $1 \mathrm{~h}$ before decapitation. Dendritic spine analysis was carried out in rats subjected to drug treatment $3 \mathrm{~h}$ before decapitation. Drug doses were selected based on our preliminary studies and published data $[39,40]$.

\subsection{Forced Swim Test (FST)}

The FST was carried out as previously described [55]. On day one of the experiment, animals were individually placed in plexiglass cylinders ( $40 \mathrm{~cm}$ in height, $18 \mathrm{~cm}$ in diameter), containing $25 \mathrm{~cm}$ of water maintained at $24-25^{\circ} \mathrm{C}$ for a $15 \mathrm{~min}$ habituation period. After removal from water, animals 
were returned to their home cages. On the second day, the rats were placed again in the cylinders, and the total duration of immobility was measured for a 5 min test period.

\subsection{Locomotor Activity}

Because some compounds may give non-specific responses in the FST (decreased immobility time evoked by enhanced general locomotor activity), spontaneous locomotor activity was recorded individually for each animal in Opto-Varimex cages (Columbus Instruments, USA) linked online to a compatible IBM PC. Each cage $(43 \times 44 \times 25 \mathrm{~cm})$ was surrounded with a $15 \times 15$ array of photocell beams located $3 \mathrm{~cm}$ from the floor surface. Interruptions of these photo beams resulted in horizontal activity defined as the distance traveled. Locomotor activity was recorded for $10 \mathrm{~min}$ and analyzed using the Auto-track software (Columbus Instruments, USA) and presented as the distance traveled in $\mathrm{cm}$.

\subsection{Zinc Restriction}

During the habituation phase, rats were fed a standard diet with $35 \mathrm{mg} \mathrm{Zn} / \mathrm{kg}$. Following the habituation phase, the animals were divided into two groups; each group was fed a zinc adequate diet of $50 \mathrm{mg} \mathrm{Zn/kg}$ or a zinc-deficient diet of $3 \mathrm{mg} \mathrm{Zn/kg}$ for 4 weeks. The animals were further used in behavioral tests (experimentally naive subjects were used only once in each behavioral test) or biochemical analysis. Diets were purchased from Altromin $\mathrm{GmbH}$ (Lage, Germany). The animals were housed 5 per cage (except for the rats used in the sucrose intake test, which were housed individually) in a controlled environment (temperature $22 \pm 2{ }^{\circ} \mathrm{C}, 12 \mathrm{~h} \mathrm{light/dark} \mathrm{cycle,} 40-50 \%$ humidity) with free access to food and water.

\subsection{Sucrose Intake Test}

Individually housed rats were fed the $\mathrm{ZnA}$ or $\mathrm{ZnD}$ diet for 4 weeks, following which the SIT was carried out. A test session was preceded by a training session. Both the training and the test sessions were conducted in home cages that were equipped with two bottles; one bottle contained a $1 \%$ sucrose solution, and the other contained sterile water. In the training session, the animals were trained to consume the $1 \%$ sucrose solution for $48 \mathrm{~h}$. To prevent the possible effects of side preference, the positions of the bottles were switched every $12 \mathrm{~h}$. Following the training session, sterile water was provided for $6 \mathrm{~h}$, while withholding food and water for the next $18 \mathrm{~h}$. The test session was performed $24 \mathrm{~h}$ after the training session and lasted $1 \mathrm{~h}$. Rats were given a choice between sterile water and the $1 \%$ sucrose solution. The sucrose intake of the rats was measured by weighing the pre-weighed bottles at the end of the test.

\subsection{Synaptosome Preparation and Western Blotting}

Tissue samples were dissected from the PFC and homogenized in ice-cold lysis buffer (A) [0.32 M sucrose, 20 mM HEPES (pH 7.4) (Bioshop, Burlington, OA, Canada); 1 mM EDTA (Sigma Aldrich, St. Louis MO, USA); $1 \mathrm{X}$ protease inhibitor cocktail (Sigma Aldrich, St. Louis, MO, USA), $5 \mathrm{mM}$ $\mathrm{NaF}$ (Sigma Aldrich, St. Louis, MO, USA) and $1 \mathrm{mM} \mathrm{NaVO3} \mathrm{(Sigma} \mathrm{Aldrich,} \mathrm{St.} \mathrm{Louis,} \mathrm{MO,} \mathrm{USA)].}$ Homogenates were then centrifuged at $2800 \mathrm{rpm}$ for $10 \mathrm{~min}$ at $4{ }^{\circ} \mathrm{C}$. The resultant pellet (nuclear fraction) was resuspended in buffer $\mathrm{A}$, and the supernatant was further spun at 12,000 rpm for $10 \mathrm{~min}$ at $4{ }^{\circ} \mathrm{C}$; the pellets obtained from this step were sonicated in protein lysis buffer (B) containing $50 \mathrm{mM}$ Tris HCl (pH 7.5) (Sigma Aldrich, St Louis, MO, USA), 150 mM NaCl (POCH Basic, Gliwice, Poland), 1\% Triton X-100 (Bioshop, Burlington, OA, Canada), 0.1\% SDS ((Sigma Aldrich, St. Louis, MO, USA), $2 \mathrm{mM}$ EDTA, $1 \mathrm{mM} \mathrm{NaVO}, 5 \mathrm{mM} \mathrm{NaF}$ and $1 \mathrm{X}$ protease inhibitor cocktail. Protein concentrations were measured using a BCA kit (Thermo Scientific, Rockford, IL, USA)). Next, the proteins were separated by SDS-PAGE and transferred to nitrocellulose membranes and blocked for $1 \mathrm{~h}$ in $1 \%$ blocking solution [BM Chemiluminescence Western Blotting Kit (Mouse/Rabbit);Mannheim Germany]. After blocking, the membranes were incubated overnight at $4{ }^{\circ} \mathrm{C}$ with the respective primary antibodies. The following 
antibodies were used: total and phospho-ERK (both at a dilution of 1:1000, phospho-Millipore, Temecula, CA, USA, total-Cell Signaling, Leiden, Netherlands), total and phospho-p70S6K (pp70S6K, Thr389) (respectively 1:1000 and 1:500, Abcam, Cambridge, UK), synapsin I (Abcam, Cambridge, UK 1:1000), GluA1 AMPA (Abcam, Cambridge, UK, 1:1000), $\beta$-actin (Sigma Aldrich, St. Louis, MO, USA, 1:12000). For the determination of the levels of total ERK and $\beta$-actin we used restore plus stripping buffer (Thermo Scientific, Rockford, IL, USA). The following day, the membranes were washed three times for $10 \mathrm{~min}$ in Tris-buffered saline with Tween (TBS-T) and incubated for $30 \mathrm{~min}$ with anti-mouse/anti-rabbit-IgG-peroxidase conjugated antibodies. This set of secondary antibodies was also a component of the BM Chemiluminescence Western Blotting Kit (Mouse/Rabbit) (Roche, Mannheim, Germany). After incubation, the membranes were washed three times for 10 min with TBS-T. In the last step, the blots were incubated with a detection reagent (Roche, Mannheim, Germany). The signals from the tested proteins were visualized and measured using a Fuji-Las1000 system and Fuji Image Gauge v.4.0 software. To check for transfer and loading, $\beta$-actin was indicated on each blot. Each signal from the phospho and total protein was divided by its corresponding $\beta$-actin signal to arrive at the final result (ratio of the optical density of a particular protein to that of $\beta$-actin). The data on the graph are expressed as \% of change vs. control.

\subsection{Morphological Analysis of Dendritic Spines}

In order to quantify dendritic spines, Golgi staining was performed using the FD Rapid GolgiStainTM Kit (FD Neuro Technologies, Inc., Columbia, MD, USA) according to the manufacturer's instructions. Three hours after i.p. administration of Ro, treated and vehicle rats were deeply anesthetized with pentobarbital, their brains were removed from the skull and rinsed in double-distilled water. Brains were immersed in impregnation solution, made by mixing equal volumes of Solutions $\mathrm{A}$ and B, overnight and then stored in fresh solution at room temperature (RT) in the dark for 2 weeks. Next, brains were transferred into Solution C overnight and then stored in fresh solution at RT for 1 week in the dark. The brains were frozen on dry ice and sliced into $100 \mu \mathrm{m}$-thick frontal sections using a freezing microtome (Reichert ( $\left.\mathrm{N}^{\circ} 17169\right)$, Wien, Austria). The sections were mounted on gelatin-coated slides (FD Neuro Technologies, Inc., Columbia, MD, USA). Dried sections were processed according to the manufacturer's instructions using Solutions D and E provided in the kit. The dendritic spines were counted on the secondary and tertiary apical dendrites of neurons in the Cg3 and IL of the medial prefrontal cortex (mPFC) using a light microscope (Leica, DMLB; Leica, Denmark) equipped with a projecting camera (Basler Vision Technologies, Germany) and a microscope stage connected to an xyz stepper (PRIOR ProScan) controlled by a computer using Visiopharm New CAST software (Visiopharm, Denmark). The analyzed area was outlined under low magnification $(\times 5)$, while spine counting was performed under $\times 100$ magnification within three stained sections from each animal (AP $=3.20$ to $2.20 \mathrm{~mm}$ from bregma) [56] using a randomized meander sampling. To ascertain relative spine density, spines on multiple dendritic branches were counted to obtain an average spine number per 10 $\mu \mathrm{m}$. The average value for each region, in each rat, was obtained, and five to six rats were analyzed per group. Microphotographs were taken using a light microscope Nikon Eclipse E600 (Nikon, Japan), equipped with a black and white camera (Leica Microsystems CMS, GmbH Germany) connected to a computer running the Leica Application Suite (LAS) version 4.5 software.

\subsection{Statistical Analysis}

Data are presented as means \pm SEM and evaluated using two way-ANOVA and Newman-Keuls multiple comparison post hoc tests when appropriate. $p<0.05$ was considered significant.

Author Contributions: B.P. and G.N. designed the studies. B.P. determined protein expression by Western Blotting and analyzed the results. B.P., B.S. and A.R.-U. Performed behavioral studies. B.P. and H.D. performed Golgi-Cox staining. H.D. analyzed dendritic spines density. B.P., B.S. and G.N. wrote the manuscript. All authors have read and agreed to the published version of the manuscript. 
Funding: This research was funded partially by a grant from the National Science Center UMO 2015/19/B/NZ4/01890 (G.N) and partially by a statutory fund from the Maj Institute of Pharmacology, PAS, Poland.

Conflicts of Interest: The authors declare no conflict of interest.

\section{References}

1. Busfield, J. Challenging claims that mental illness has been increasing and mental well-being declining. Soc. Sci. Med. 2012, 75, 581-588. [CrossRef] [PubMed]

2. Hidaka, B.H. Depression as a disease of modernity: Explanations for increasing prevalence. J. Affect. Disord. 2012, 140, 205-214. [CrossRef]

3. Wittchen, H.U.; Jacobi, F.; Rehm, J.; Gustavsson, A.; Svensson, M.; Jonsson, B.; Olesen, J.; Allgulander, C.; Alonso, J.; Faravelli, C.; et al. The size and burden of mental disorders and other disorders of the brain in Europe 2010. Eur. Neuropsychopharmacol. 2011, 21, 655-679. [CrossRef] [PubMed]

4. Rosenblat, J.D.; McIntyre, R.S.; Alves, G.S.; Fountoulakis, K.N.; Carvalho, A.F. Beyond Monoamines-Novel Targets for Treatment-Resistant Depression: A Comprehensive Review. Curr. Neuropharmacol. 2015, 13, 636-655. [CrossRef] [PubMed]

5. Szewczyk, B.; Szopa, A.; Serefko, A.; Poleszak, E.; Nowak, G. The role of magnesium and zinc in depression: Similarities and differences. Magnes. Res. 2018, 31, 78-89. [CrossRef]

6. Vashum, K.P.; McEvoy, M.; Milton, A.H.; McElduff, P.; Hure, A.; Byles, J.; Attia, J. Dietary zinc is associated with a lower incidence of depression: Findings from two Australian cohorts. J. Affect. Disord. 2014, 166, 249-257. [CrossRef]

7. Jacka, F.N.; Maes, M.; Pasco, J.A.; Williams, L.J.; Berk, M. Nutrient intakes and the common mental disorders in women. J. Affect. Disord. 2012, 141, 79-85. [CrossRef]

8. Hansen, C.R., Jr.; Malecha, M.; Mackenzie, T.B.; Kroll, J. Copper and zinc deficiencies in association with depression and neurological findings. Biol. Psychiatry 1983, 18, 395-401.

9. Maes, M.; Bosmans, E.; De Jongh, R.; Kenis, G.; Vandoolaeghe, E.; Neels, H. Increased serum IL-6 and IL-1 receptor antagonist concentrations in major depression and treatment resistant depression. Cytokine 1997, 9, 853-858. [CrossRef] [PubMed]

10. Lehto, S.M.; Ruusunen, A.; Tolmunen, T.; Voutilainen, S.; Tuomainen, T.P.; Kauhanen, J. Dietary zinc intake and the risk of depression in middle-aged men: A 20-year prospective follow-up study. J. Affect. Disord. 2013, 150, 682-685. [CrossRef]

11. Marcellini, F.; Giuli, C.; Papa, R.; Gagliardi, C.; Dedoussis, G.; Herbein, G.; Fulop, T.; Monti, D.; Rink, L.; Jajte, J.; et al. Zinc status, psychological and nutritional assessment in old people recruited in five European countries: Zincage study. Biogerontology 2006, 7, 339-345. [CrossRef] [PubMed]

12. Markiewicz-Zukowska, R.; Gutowska, A.; Borawska, M.H. Serum zinc concentrations correlate with mental and physical status of nursing home residents. PLoS ONE 2015, 10, e0117257. [CrossRef]

13. Siwek, M.; Szewczyk, B.; Dudek, D.; Styczen, K.; Sowa-Kucma, M.; Mlyniec, K.; Siwek, A.; Witkowski, L.; Pochwat, B.; Nowak, G. Zinc as a marker of affective disorders. Pharmacol. Rep. 2013, 65, 1512-1518. [CrossRef]

14. McLoughlin, I.J.; Hodge, J.S. Zinc in depressive disorder. Acta Psychiatr. Scand. 1990, 82, 451-453. [CrossRef] [PubMed]

15. Maes, M.; De Vos, N.; Demedts, P.; Wauters, A.; Neels, H. Lower serum zinc in major depression in relation to changes in serum acute phase proteins. J. Affect. Disord. 1999, 56, 189-194. [CrossRef]

16. Siwek, M.; Dudek, D.; Schlegel-Zawadzka, M.; Morawska, A.; Piekoszewski, W.; Opoka, W.; Zieba, A.; Pilc, A.; Popik, P.; Nowak, G. Serum zinc level in depressed patients during zinc supplementation of imipramine treatment. J. Affect. Disord. 2010, 126, 447-452. [CrossRef]

17. Mlyniec, K.; Davies, C.L.; Budziszewska, B.; Opoka, W.; Reczynski, W.; Sowa-Kucma, M.; Doboszewska, U.; Pilc, A.; Nowak, G. Time course of zinc deprivation-induced alterations of mice behavior in the forced swim test. Pharmacol. Rep. 2012, 64, 567-575. [CrossRef]

18. Mlyniec, K.; Nowak, G. Zinc deficiency induces behavioral alterations in the tail suspension test in mice. Effect of antidepressants. Pharmacol. Rep. 2012, 64, 249-255. [CrossRef] 
19. Whittle, N.; Lubec, G.; Singewald, N. Zinc deficiency induces enhanced depression-like behaviour and altered limbic activation reversed by antidepressant treatment in mice. Amino Acids 2009, 36, 147-158. [CrossRef]

20. Doboszewska, U.; Sowa-Kucma, M.; Mlyniec, K.; Pochwat, B.; Holuj, M.; Ostachowicz, B.; Pilc, A.; Nowak, G.; Szewczyk, B. Zinc deficiency in rats is associated with up-regulation of hippocampal NMDA receptor. Prog. Neuropsychopharmacol. Biol. Psychiatry 2015, 56, 254-263. [CrossRef]

21. Doboszewska, U.; Szewczyk, B.; Sowa-Kucma, M.; Mlyniec, K.; Rafalo, A.; Ostachowicz, B.; Lankosz, M.; Nowak, G. Antidepressant activity of fluoxetine in the zinc deficiency model in rats involves the NMDA receptor complex. Behav. Brain Res. 2015, 287, 323-330. [CrossRef] [PubMed]

22. Tassabehji, N.M.; Corniola, R.S.; Alshingiti, A.; Levenson, C.W. Zinc deficiency induces depression-like symptoms in adult rats. Physiol. Behav. 2008, 95, 365-369. [CrossRef] [PubMed]

23. Yang, C.; Yang, J.; Luo, A.; Hashimoto, K. Molecular and cellular mechanisms underlying the antidepressant effects of ketamine enantiomers and its metabolites. Transl. Psychiatry 2019, 9, 280. [CrossRef] [PubMed]

24. Zarate, C.A., Jr.; Niciu, M.J. Ketamine for depression: Evidence, challenges and promise. World Psychiatry 2015, 14, 348-350. [CrossRef] [PubMed]

25. Berman, R.M.; Cappiello, A.; Anand, A.; Oren, D.A.; Heninger, G.R.; Charney, D.S.; Krystal, J.H. Antidepressant effects of ketamine in depressed patients. Biol. Psychiatry 2000, 47, 351-354. [CrossRef]

26. Zarate, C.A., Jr.; Singh, J.B.; Carlson, P.J.; Brutsche, N.E.; Ameli, R.; Luckenbaugh, D.A.; Charney, D.S.; Manji, H.K. A randomized trial of an N-methyl-D-aspartate antagonist in treatment-resistant major depression. Arch. Gen. Psychiatry 2006, 63, 856-864. [CrossRef]

27. Daly, E.J.; Singh, J.B.; Fedgchin, M.; Cooper, K.; Lim, P.; Shelton, R.C.; Thase, M.E.; Winokur, A.; Van Nueten, L.; Manji, H.; et al. Efficacy and Safety of Intranasal Esketamine Adjunctive to Oral Antidepressant Therapy in Treatment-Resistant Depression: A Randomized Clinical Trial. JAMA Psychiatry 2018, 75, 139-148. [CrossRef]

28. DiazGranados, N.; Ibrahim, L.A.; Brutsche, N.E.; Ameli, R.; Henter, I.D.; Luckenbaugh, D.A.; Machado-Vieira, R.; Zarate, C.A., Jr. Rapid resolution of suicidal ideation after a single infusion of an N-methyl-D-aspartate antagonist in patients with treatment-resistant major depressive disorder. J. Clin. Psychiatry 2010, 71, 1605-1611. [CrossRef]

29. Canuso, C.M.; Singh, J.B.; Fedgchin, M.; Alphs, L.; Lane, R.; Lim, P.; Pinter, C.; Hough, D.; Sanacora, G.; Manji, H.; et al. Efficacy and Safety of Intranasal Esketamine for the Rapid Reduction of Symptoms of Depression and Suicidality in Patients at Imminent Risk for Suicide: Results of a Double-Blind, Randomized, Placebo-Controlled Study. Am. J. Psychiatry 2018, 175, 620-630. [CrossRef]

30. De Berardis, D.; Fornaro, M.; Valchera, A.; Cavuto, M.; Perna, G.; Di Nicola, M.; Serafini, G.; Carano, A.; Pompili, M.; Vellante, F.; et al. Eradicating Suicide at Its Roots: Preclinical Bases and Clinical Evidence of the Efficacy of Ketamine in the Treatment of Suicidal Behaviors. Int. J. Mol. Sci. 2018, 19, 2888. [CrossRef]

31. De Berardis, D.; Tomasetti, C.; Pompili, M.; Serafini, G.; Vellante, F.; Fornaro, M.; Valchera, A.; Perna, G.; Volpe, U.; Martinotti, G.; et al. An Update on Glutamatergic System in Suicidal Depression and on the Role of Esketamine. Curr. Top. Med. Chem. 2020, 20, 554-584. [CrossRef] [PubMed]

32. Li, N.; Liu, R.J.; Dwyer, J.M.; Banasr, M.; Lee, B.; Son, H.; Li, X.Y.; Aghajanian, G.; Duman, R.S. Glutamate $\mathrm{N}$-methyl-D-aspartate receptor antagonists rapidly reverse behavioral and synaptic deficits caused by chronic stress exposure. Biol. Psychiatry 2011, 69, 754-761. [CrossRef] [PubMed]

33. Yang, B.K.; Qin, J.; Nie, Y.; Chen, J.C. Sustained antidepressant action of the N-methyl-D-aspartate receptor antagonist MK-801 in a chronic unpredictable mild stress model. Exp. Ther. Med. 2018, 16, 5376-5383. [CrossRef]

34. Cunningham, M.G.; Ames, H.M.; Christensen, M.K.; Sorensen, J.C. Zincergic innervation of medial prefrontal cortex by basolateral projection neurons. Neuroreport 2007, 18, 531-535. [CrossRef] [PubMed]

35. Frederickson, C.J.; Danscher, G. Zinc-containing neurons in hippocampus and related CNS structures. Prog. Brain Res. 1990, 83, 71-84. [CrossRef]

36. Maret, W. Zinc biochemistry: From a single zinc enzyme to a key element of life. Adv. Nutr. 2013, 4, 82-91. [CrossRef]

37. Suh, S.W.; Chen, J.W.; Motamedi, M.; Bell, B.; Listiak, K.; Pons, N.F.; Danscher, G.; Frederickson, C.J. Evidence that synaptically-released zinc contributes to neuronal injury after traumatic brain injury. Brain Res. 2000, 852, 268-273. [CrossRef] 
38. Mlyniec, K.; Gawel, M.; Nowak, G. Study of antidepressant drugs in GPR39 (zinc receptor(-)/(-)) knockout mice, showing no effect of conventional antidepressants, but effectiveness of NMDA antagonists. Behav. Brain Res. 2015, 287, 135-138. [CrossRef]

39. Li, N.; Lee, B.; Liu, R.J.; Banasr, M.; Dwyer, J.M.; Iwata, M.; Li, X.Y.; Aghajanian, G.; Duman, R.S. mTOR-dependent synapse formation underlies the rapid antidepressant effects of NMDA antagonists. Science 2010, 329, 959-964. [CrossRef]

40. Pochwat, B.; Rafalo-Ulinska, A.; Domin, H.; Misztak, P.; Nowak, G.; Szewczyk, B. Involvement of extracellular signal-regulated kinase (ERK) in the short and long-lasting antidepressant-like activity of NMDA receptor antagonists (zinc and Ro 25-6981) in the forced swim test in rats. Neuropharmacology 2017, 125, 333-342. [CrossRef]

41. Doboszewska, U.; Szewczyk, B.; Sowa-Kucma, M.; Noworyta-Sokolowska, K.; Misztak, P.; Golebiowska, J.; Mlyniec, K.; Ostachowicz, B.; Krosniak, M.; Wojtanowska-Krosniak, A.; et al. Alterations of Bio-elements, Oxidative, and Inflammatory Status in the Zinc Deficiency Model in Rats. Neurotox. Res. 2016, 29, 143-154. [CrossRef]

42. Paoletti, P.; Vergnano, A.M.; Barbour, B.; Casado, M. Zinc at glutamatergic synapses. Neuroscience 2009, 158, 126-136. [CrossRef] [PubMed]

43. Pochwat, B.; Nowak, G.; Szewczyk, B. An update on NMDA antagonists in depression. Expert Rev. Neurother 2019, 19, 1055-1067. [CrossRef]

44. Ghosal, S.; Duman, C.H.; Liu, R.J.; Wu, M.; Terwilliger, R.; Girgenti, M.J.; Wohleb, E.; Fogaca, M.V.; Teichman, E.M.; Hare, B.; et al. Ketamine rapidly reverses stress-induced impairments in GABAergic transmission in the prefrontal cortex in male rodents. Neurobiol. Dis. 2019, 134, 104669. [CrossRef] [PubMed]

45. Talbot, J.N.; Geffert, L.M.; Jorvig, J.E.; Goldstein, R.I.; Nielsen, C.L.; Wolters, N.E.; Amos, M.E.; Munro, C.A.; Dallman, E.; Mereu, M.; et al. Rapid and sustained antidepressant properties of an NMDA antagonist/monoamine reuptake inhibitor identified via transporter-based virtual screening. Pharmacol. Biochem. Behav. 2016, 150, 22-30. [CrossRef] [PubMed]

46. Frazzini, V.; Granzotto, A.; Bomba, M.; Massetti, N.; Castelli, V.; d’Aurora, M.; Punzi, M.; Iorio, M.; Mosca, A.; Delli Pizzi, S.; et al. The pharmacological perturbation of brain zinc impairs BDNF-related signaling and the cognitive performances of young mice. Sci. Rep. 2018, 8, 9768. [CrossRef] [PubMed]

47. Christoffel, D.J.; Golden, S.A.; Russo, S.J. Structural and synaptic plasticity in stress-related disorders. Rev. Neurosci. 2011, 22, 535-549. [CrossRef]

48. Krzystyniak, A.; Baczynska, E.; Magnowska, M.; Antoniuk, S.; Roszkowska, M.; Zareba-Koziol, M.; Das, N.; Basu, S.; Pikula, M.; Wlodarczyk, J. Prophylactic Ketamine Treatment Promotes Resilience to Chronic Stress and Accelerates Recovery: Correlation with Changes in Synaptic Plasticity in the CA3 Subregion of the Hippocampus. Int. J. Mol. Sci. 2019, 20. [CrossRef]

49. Duman, C.H.; Duman, R.S. Spine synapse remodeling in the pathophysiology and treatment of depression. Neurosci. Lett. 2015, 601, 20-29. [CrossRef]

50. Goldin, M.; Segal, M. Protein kinase C and ERK involvement in dendritic spine plasticity in cultured rodent hippocampal neurons. Eur. J. Neurosci. 2003, 17, 2529-2539. [CrossRef]

51. Ota, K.T.; Liu, R.J.; Voleti, B.; Maldonado-Aviles, J.G.; Duric, V.; Iwata, M.; Dutheil, S.; Duman, C.; Boikess, S.; Lewis, D.A.; et al. REDD1 is essential for stress-induced synaptic loss and depressive behavior. Nat. Med. 2014, 20, 531-535. [CrossRef] [PubMed]

52. Kumar, V.; Zhang, M.X.; Swank, M.W.; Kunz, J.; Wu, G.Y. Regulation of dendritic morphogenesis by Ras-PI3K-Akt-mTOR and Ras-MAPK signaling pathways. J. Neurosci. 2005, 25, 11288-11299. [CrossRef] [PubMed]

53. Yang, C.; Ren, Q.; Qu, Y.; Zhang, J.C.; Ma, M.; Dong, C.; Hashimoto, K. Mechanistic Target of Rapamycin-Independent Antidepressant Effects of (R)-Ketamine in a Social Defeat Stress Model. Biol. Psychiatry 2018, 83, 18-28. [CrossRef] [PubMed]

54. Yang, C.; Shirayama, Y.; Zhang, J.C.; Ren, Q.; Yao, W.; Ma, M.; Dong, C.; Hashimoto, K. R-ketamine: A rapid-onset and sustained antidepressant without psychotomimetic side effects. Transl. Psychiatry 2015, 5, e632. [CrossRef] 
55. Szewczyk, B.; Pochwat, B.; Rafalo, A.; Palucha-Poniewiera, A.; Domin, H.; Nowak, G. Activation of mTOR dependent signaling pathway is a necessary mechanism of antidepressant-like activity of zinc. Neuropharmacology 2015, 99, 517-526. [CrossRef]

56. Paxinos, G.; Watson, C. The Rat Brain in Stereotaxic Coordinates, 2nd ed.; Academic Press: San Diego, CA, USA, 1986.

(C) 2020 by the authors. Licensee MDPI, Basel, Switzerland. This article is an open access article distributed under the terms and conditions of the Creative Commons Attribution (CC BY) license (http://creativecommons.org/licenses/by/4.0/). 